\title{
Practical Application of Training tasks Based on Flexible Manufacturing System
}

\author{
Hongmei Fan \\ School of Automation, Nanjing Institute of Technology ,Nanjing, 211167, China \\ zdhxfhm@njit.edu.cn
}

Keywords: Flexible Manufacturing System, Training Task, Practical Application

\begin{abstract}
Aiming at the characteristics of the flexible manufacturing system, the equipment composition and the hardware architecture of the flexible manufacturing system is described in this paper. Taking the parallel machine fabrication process as an example, the automated production process is elaborated. Combined with laboratory equipment and the professional knowledge and different teaching characteristics, the teaching programs of flexible manufacturing system is presented. The laboratory project is planned and is implemented in specific engineering training tasks, the professional knowledge of students on both the breadth and depth has been expanded, the experimental skills and innovative capacity to improve teaching effectiveness has been significantly improved as well.
\end{abstract}

\section{Introduction}

A flexible manufacturing system(FMS) is a highly automated group technology machine cell, consisting of a group of processing workstations(usually CNC machine tools), interconnected by an automated material handling and storage system, and controlled by a distributed computer system. The reason the FMS is called flexible is that it is capable of processing a variety of different part styles simultaneously at the various workstations, and the mix of part styles and quantities of production can be adjusted in response to changing demand patterns[1]. At present, the production style of many manufacturing enterprises is transited from single variety and high volume to multi-variety and medium or low volume, more and more manufacturing enterprises choice to use FMS in this period, FMS is penetrated into every manufacturing field.

At present, the traditional experiment equipments can not satisfy for the professional knowledge of the college graduates on the depth and breadth. So it is necessary to introduce the engineering training tasks in the flexible manufacturing system to improve the cultivation of the graduate' flexible manufacturing knowledge and its sci-technology innovation abilities. The FMS utilized in this paper is a stable and reliable FMS, which has high cost effectiveness and is based on field bus technology. The system has functions of comprehensive regulation, material handling system control, parallel machine fabrication, serial robot control and network data exchange. The FMS provides an opening platform for practical teaching and researches

\section{The characteristics of FMS[2]}

1. High integration. All the equipments of the system is integrated highly and effectively by ProfiBus-DP industrial field bus, it is very convenient to manage the equipment.

2. Modularization. The manufacturing and inspection equipments have two operation mode, that is the single machine \& on-line mode. The hardware and software of all the cellular equipments can be operated respectively, the single project can be researched and developed in this single machine platform. It realizes the modern teaching and training commodiously.

3. Industrialization. All the equipments of the whole system use the standard industrial equipment, so it can implement industrial production instead of simulation processing.

4. Interactive graphical user interface. The software of FMS is based on Windows operation system, which has the virtue of friendly user interface, easy to learn and high automation, the teachers and students can grasp the system operation in a short time. 
5. High performance. The servo system of the FMS is composed of opening motion controller and servo motor. Which is high speed, high accuracy and low noise. The primary material handling system is the standard system, such as belt conveyor and curve conveyor. The secondary material handling system is utilized 6-DOF serial robot. So the production efficiency is improved highly.

6. In-time monitoring. The production procedure is monitoring and managing in time, hence, it is very easy to use, develop and fault detect the system.

\section{The FMS constitute}

The FMS of this paper is composed of automated warehouse, automated handling equipment, CCD detector, 6 DOF serial transfer robot, 6 DOF parallel machine tool and relative accessory equipments[3]. The hardware architecture is illustrated in fig.1. The work procedure is as follows:

1 . The system is powered on.

2. The master computer checks the raw material warehouse, if there is no raw material in the warehouse, then the in-warehouse operation is needed.

3. A "manufacturing" task is issued by the production management system of the master computer, the FMS executes the production task automatically.

4. The palletizer removes the part or raw material from the raw material warehouse, and loads it on the warehouse-out platform.

5. The material handling system transports it to a fixed position.

6. The 6 DOF serial transfer robot loads it on the table of the parallel machine tool.

7. After fabrication, the transfer robot unloads the finished part, and transfers it on the belt conveyor.

8. The inspect system detects the finished part.

9. If no defect, then the finished part is stored in the finished product warehouse. The production procedure is ended.

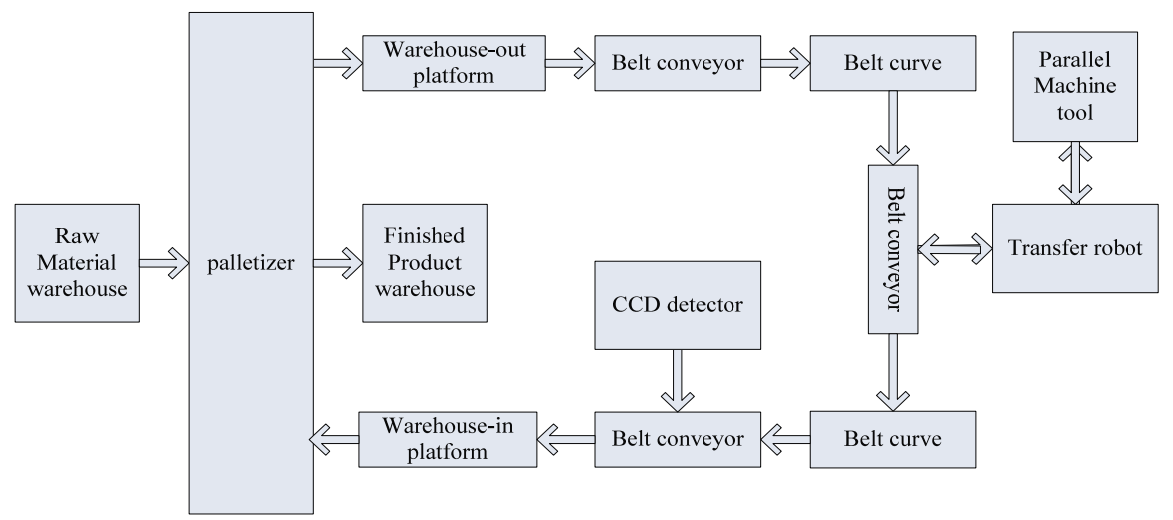

Fig.1 FMS hardware architecture

In order to simulating the real industrial production process, the flexible manufacturing teaching experimental system is established according to the industrial FMS standard, as depicted in fig.2.

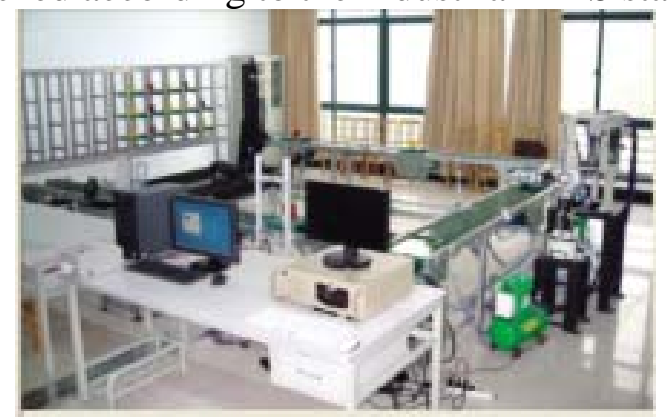

Fig.2 Flexible manufacturing teaching experimental system 


\section{Training tasks}

The task of training project is firmly similar with the mission in the industrial processing. Based on both actual product receipts and analysis, this FMS provides not only the typical function in flexible manufacturing system but also the task in the corresponding job position, and also summarizes the tasks in the working process, and separates them into a lot of independent units. Each unit can accomplish some training tasks. There are 3 main units in this FMS [4], each unit has different training tasks.

Warehouse management unit. In this FMS, the storage of raw material and finished product is a three dimensional warehouse. The function of this unit is raw material warehouse-out, transport, finished product warehouse-in. The operation of warehouse-out and warehouse-in is achieved by palletizer, and the transport both the raw material and the finished product is accomplished by material handling system, which has three linear belt conveyors and two 90 degree curve belt conveyors. There are 3 training tasks in this unit.

1. Automated material handling system cognitive training. This is the basic training task, and is suitable for the freshman and sophomore. Through this task, the students learn what are the functions of the handling system, which material handling equipment typically used in an FMS and how the FMS layout.

2. The operation task of automated warehouse. The automated warehouse operation consists of picking up the load at the input/output point, traveling to the storage location, placing the load in rack, traveling empty to the retrieval location, retrieve a load, return to the I/O point, and deposit the load at the I/O point.

3. Task of computer storage management system for automated warehouse. Which is an integrated innovation training task. Based on the study of existing automated warehouse, combined with the actual situation, the students can design and develop a warehouse management system. Which functions should including storage management, database management, scrap management, query management, cargo statistics, data maintenance, user management and system management, etc.

Serial robot control unit. 6 DOF serial robot loads and unloads part is accomplished under the control of this unit. The interface of this unit is shown in fig.3.The control software is developed based on EVC[4].The main function of this unit is as follows.

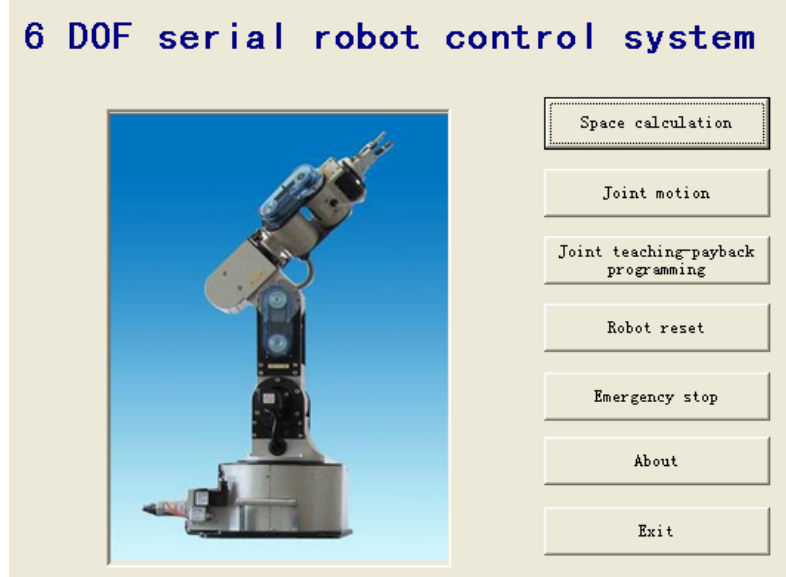

Fig. 3 Serial robot control interface

1. Space calculation. Space calculation includes kinematics positive \& reverse solution for the 6 DOF serial robot. There are two parameter input frame, one is the position and posture of the end effector, the other is the 6 joints' angle. If we input the 6 joint' angle parameters and click the positive solution button, the relative position and posture of the end effector will be displayed in the position and posture frame, vice versa.

2. Joint motion. The 6 joints can be tested respectively. Choice a joint in the joint choice frame, the joint orientation, the motion mode and the start mode first, then set the motion parameters(the motion velocity, the target position), finally, click the start button, observe whether the joint moves as expected. When the stop button is clicked during the motion period, the joint motion will stop 
immediately. If the manipulator open button is clicked, the manipulator will open and the button will become "manipulator close", and click this button again, the manipulator will close.

\section{Robot teach programming}

The state and the coordinate of each joint can be displayed and saved as a teach programming. the procedure is as follows:

- Start the control software, observe whether every joint of the robot is the zero position, if not, click the reset button, reset the robot.

- Click the "+" or "-” button in the joint motion frame, control the joint move to the target position, then click the "record" button, record this point, this record also be added to the teaching list.

- If all the teaching is finished, then click the "save" button, the teaching file is saved.

- Click the "open" button, the teaching file saved before can be loaded in the teaching list, then choice the teach mode, "single", teaching only once, "continuous" teaching repeatedly until the "stop" button is clicked.

Parallel machine tool control. In this system, the machining station is a parallel machine tool. Considering the real time and stability of the system, the control system of this unit is developed by EVC also[5-8], the main interface is depicted as fig.4.

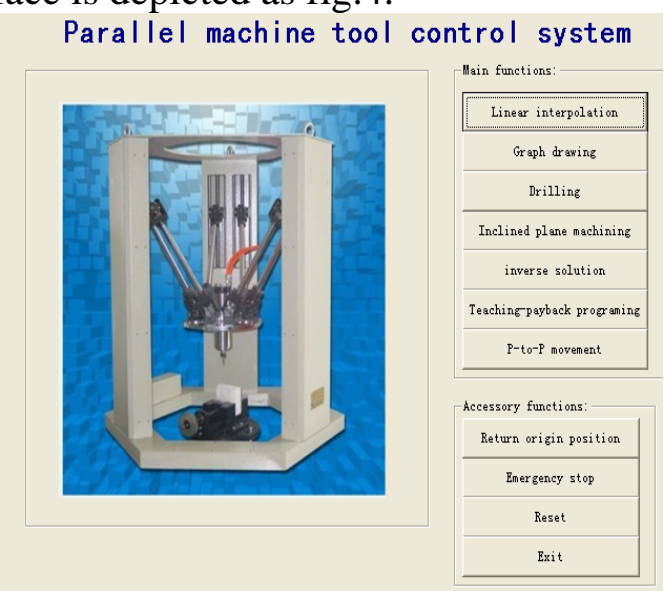

Fig.4 Parallel machine tool control interface

1. Inverse solution. When the parallel machine tool is in motion, the driven style is equal to the change of $\mathrm{Z}$ coordinate of point $\mathrm{B}_{\mathrm{i}}$, while $\mathrm{X}$ and $\mathrm{Y}$ coordinate remains the same. So let $L_{i}=L_{i}^{\prime}$, then $\mathrm{Z}$ coordinate change of $B_{i}$ can be determined, this is the length that the linkage should move, thus the inverse solution can be solved by the given output position. After inputting the relative data about the first and second point pose, then clicking the count button, the motor position about the first and second point and the pulse number needed moving from the first point to the second point is calculated and displayed in the motor parameter area.

2. Point to point movement. By using (12), the movement form point $\mathrm{P}$ to point $\mathrm{P}^{\prime}$ can be achieved by controlling the elongation of each linkage. However, the motion process is a linear movement of each linkage respectively, although the outmost result is moving from point $\mathrm{P}$ to point $\mathrm{P}^{\prime}$, the middle trajectory is not always line.

3. Linear interpolation. In linear interpolation, the line is divided into $\mathrm{N}$ micro-lines. If $\mathrm{N}$ is large enough, then the step of every motion is very small, so the trajectory from point to point can be considered as line, thus the whole motion trajectory is a line which is composed of many macro lines. the user must input the current pose parameters, destination pose parameters(X,Y and $\mathrm{Z}$ coordinate, $\alpha, \beta, \gamma$ rotate angle), and the interpolation step. In order to observing the result of the interpolation trajectory, a special brush is amounted on the upper platform, and a drawing board is installed on the lower platform. Setting all the current pose parameters zero, the parameter $\mathrm{z}$ of the destination pose is -25, others are zero, then clicking the step motion button in the P-to-P movement interface, let the brush touch the drawing board, then change the parameter $\mathrm{X}$ and $\mathrm{Y}$ of the destination pose, click the interpolation button, the trajectory of linear interpolation is drawn on the board.

4. Grooving and drilling fabrication. The drilling fabrication principle is that the milling cutter rotating and moving straight down at the same time, after touching the workpart, it moves slowly down 
$\mathrm{m}$ millimeter, then a m millimeter depth hole is drilled. The principle of grooving is that the milling cutter rotating and moving straight down at the same time, after touching the work-part, it moves slowly down $m$ millimeter, and then feed $n$ millimeter in horizontal direction, thus a grooving is milled which depth is $m$ millimeter and length is $n$ millimeter

5. Inclined plane machining. The principle of inclined plane machining is that the milling cutter has a angle with vertical direction, it moves along with one face of the work-part, when it rotates, one level of the work-part is machined, thus through multi to and fro motion, an inclined plane is fabricated.

6. Teaching and playback. Robot teaching and playback is two process, which teaching and playback robot realizes its operations. In teaching process, operator manipulates the robot via teach pendant or teaching software interface, the teaching software installed in the computer system records the motion information automatically, such as the start point and endpoint of every motion trajectory, motion style, motion speed, etc., and stores the data in computer memory. In playback process, the motion style and motion speed stored in the memory is playback, after that the middle points of each trajectory are calculated through interpolation algorithm, these points serve as the instruction of motor movement, thereby the teaching operation process is playback.

Experimental project level. In order to ultimately increasing the equipment utilization, the experimental project is divided into three levels, each level has different training task. The first level is cognitive training, the students learn the basic knowledge and working principle of each project. The second level is professional skills training, Which focuses on the training of operational skills and professional knowledge. The third level is comprehensive innovation training, which aims at improving the comprehensive quality and the innovation ability of the students, as illustrated in table 1.

Table 1 training task

\begin{tabular}{|c|c|c|c|}
\hline Cognitive training task & \multicolumn{2}{|c|}{ Professional skill training task } & Comprehensive innovation training task \\
\hline \multirow{3}{*}{$\begin{array}{l}\text { Automated material } \\
\text { handling system cognitive } \\
\text { training }\end{array}$} & \multicolumn{2}{|c|}{ Operation task of automated warehouse } & \multirow{2}{*}{$\begin{array}{l}\text { Computer storage management system } \\
\text { for automated warehouse }\end{array}$} \\
\hline & \multirow{3}{*}{$\begin{array}{l}\text { Serial } \\
\text { robot }\end{array}$} & Space calculation & \\
\hline & & Joint motion & \multirow{3}{*}{ Comprehensive part machining } \\
\hline \multirow{3}{*}{$\begin{array}{l}\text { Serial robot mechanical } \\
\text { construction and working } \\
\text { principle }\end{array}$} & & Robot teach programming & \\
\hline & \multirow{6}{*}{$\begin{array}{l}\text { Parallel } \\
\text { machine }\end{array}$} & Inverse solution & \\
\hline & & $\mathrm{P}$ to $\mathrm{P}$ movement & \multirow{3}{*}{$\begin{array}{l}\text { Industrial configuration } \\
\text { programming }\end{array}$} \\
\hline \multirow{3}{*}{$\begin{array}{l}\text { Parallel machine } \\
\text { mechanical construction } \\
\text { and working principle }\end{array}$} & & Linear interpolation & \\
\hline & & Grooving and drilling & \\
\hline & & Inclined plane machining & \multirow{3}{*}{ Network cabling } \\
\hline \multirow{2}{*}{$\begin{array}{l}\text { Principle of AC servo drive } \\
\text { and step drive }\end{array}$} & & Teaching and playback & \\
\hline & \multicolumn{2}{|c|}{ Motion controller programming } & \\
\hline
\end{tabular}

\section{Conclusion}

Flexible automated technology is an important trend of world machinery manufacturing industry. The flexible manufacturing teaching system presented in this paper is used in teaching and training. The student should master the professional knowledge of machinery, electronic, electric, auto-control and numerical control through this system. By training, students should have the ability of debugging, running, maintaining the mechatronics equipment, programming part process, inspecting industrial product, etc. This system provides an teaching and researching platform for both teachers and students, it has a favorable practice value.

\section{Acknowledgements}

This is supported by Nanjing Institute of Technology foundation of China(CKJ2011005).

\section{References}

[1] Mikell P. Groover, Automation,Production System, and Computer-integrated Manufacturing, Qinghua University press, China 2006. 
[2] Y.F.Lei, in: Practical application of engineering training based on flexible manufacturing systems, Experiment science and technology, Vol.11(2013),p.127-130.

[3] J.W. Zhao, B.Biao in: flexible manufacturing system based on training tasks, Experimental Technology and Management. Vol.29(2011), p.127-129.

[4] H.M.Fan. in: Kinematics Simulation and Control System Design of Serial Robot Based on ADAMS and Pro/E,Applied Mechanics and Material. Vol.187(2012),p.186-189.

[5] D.Stewart, in:A platform with six degree of freedom Ime Proc. 80,1965, Part1(15):pp. 371368.

[6] S.-Zhang, Parallel Kinematic Machine .Beijing: China Machine Press, 2003.

[7] D. M. Ku,in:Direct displacement analysis of a platform mechanism, Mechanism and machine Theory. 1999, 34(5):pp:453-465

[8] J.P. Merlet, Parallel Robot, springer,2006. 